\title{
Significance of Self-regulation for the Professional Development of Prospective Teachers
}

\author{
Guzalia Rasikhovna Shagivaleeva
}

Vilya Rustemovna Bildanova

Galia Kamilyevna Biserova

Elena Michailovna Yusupova

Irina Anatolevna Talysheva

Kazan Federal University, Russia, Republic of Tatarstan, 423600, Elabuga, Kazanskaya Street, 89

\author{
Doi:10.5901/mjss.2015.v6n5s1p128
}

\section{Abstract}

The aim of present study is investigating the role of self-regulation in professional development of prospective teachers. Welldeveloped self-regulation may be defined as a person's ability to adjust his or hers behavior to the conventional moral principles and values, as well as with professional requirements. Teacher's self-regulation includes his active relationship with the students and with himself, his social affirmations, experience and interests. It can be concluded that the development of self-regulation basics happens during the period of professional learning, when the personality settlement occurs. Each teacher also discovers and uses his own methods and means of self-regulation during his professional activity, which helps him to affect his emotions and to control and regulate external signs of current psychological state.

Keywords: personality and pedagogic self-regulation, moral self-regulation, professional development, professional behavior, selfregulation

\section{Introduction}

\subsection{Psychology of pedagogic self-regulation}

Significance of present study is related to the fact that modern educational system, due to the occurring humanitarian and democratic tendencies, has extremely high requirements towards personal and professional qualities of the teacher. Such requirements become serious external reasons for teachers' self-development. This implies the increase of professional culture level, fulfilling the need to change oneself, skills of creative self-development, building one's professional selfconfidence. Self-regulation is a highly significant aspect of a teacher's professional activity.

A young person's development as a prospective specialist and teacher happens throughout the professional training. Self-regulation of the activity and personality reaches the highest efficiency level during the professional development, i.e. during the period of higher education (Tkacheva, 2010). The period of higher education becomes a basis for prospective professional activity. Studentship has high amounts of emotional experiences, which affects the lifestyle. On the other hand, in this period of life a young person rarely thinks about his health and is certain that his physical and mental resources are unlimited, which therefore may decrease his abilities to relax, rest and sleep. During the studentship years a person uses various means that might not always be health-oriented. Students' environment provides overloads of all types. However, the future professional develops during this period, and the state of his mental health directly affects the success of his learning activity and lifestyle, which is very significant for the society (Mensh, 2012).

The success in prospective pedagogical activity, which can be reached only in the state of general satisfaction with one's own personality and professional achievements, highly depends on the ability of a prospective teacher to regulate his professional behavior, professional activity and personality characteristics.

Self-regulation - (from Latin regulare - to regulate, put in order) - is generally an influence on a system with the aim of maintaining necessary measures of its operation, which is provided by internal changes of the system according to the laws of its organization (Dushkov et al., 2005). Significant impact on solving the problems of self-regulation was made by the scientists, who explored this phenomenon in various types of activity. For example, B.F. Lomov noted that "by 
studying the activity, psychology reveals the mechanisms of psychological regulation of this activity, i.e. it reveals the processes, which provides the activity compliance with its object, means and conditions" (Lomov, 1984).

\subsection{Personality and pedagogic self-regulation}

Personality and pedagogic self-regulation is defined as a whole, unified psychological and behavioral characteristic, which presents as an ability to reflect, to conduct integral analysis and probability prognosis of one's own activity. It includes the behavior itself, self-analysis, self-control, self-correction of the actions in accordance with social standards, values and behavioral norms. Personality and pedagogic self-regulation is also studied in context of pedagogic culture theory as one of its basic components, along with the other components. L.V. Zanina and E.N. Mashtakova describe pedagogic culture as an integral system of humanitarian pedagogic values, creative means of pedagogic activity and of professional pedagogic behavior, all of which are based on the potential of constant professional and personal life-long self-development and self-education. They describe the following components of this system:

1. Humanistic pedagogic position, which includes the initial individual position, systems of moral beliefs, creative and reflexive components. Each of these characteristics has its own structure and determines various aspects of teacher's personality professional self-realization.

2. Professional and personality qualities of the teacher, such as empathy, tolerance, creativity, ability to reflect.

3. Tolerance presents as a personality trait in relation to beliefs, affirmations, points of view, positions and actual behavior of different people.

4. Creativity is the readiness to productively re-think the main professional activity fields. The significance of teacher's creativity is defined by the wide variety of innovations and great amount of alternative pedagogic systems. Teacher's participation in pedagogic creativity is described as "the most effective factor" in the characteristic of his pedagogic culture level.

5. Ability to reflect is the skill of the conscience to focus on itself and observe itself as an object, which has its own specific activity and knowledge.

6. Professional knowledge is a high level of theoretic generalization and implication to the standard situations (Zanina, 1994).

Humanitarian and democratic tendencies in social processes, happening in the society and in school, determine the predominant need to address the internal processes and resources, personality potential of the teacher (Bildanova, Shagivaleeva, 2009).

The need in teacher's well-integrated and creative personality, which successfully adjusts its affirmations and transforms itself, is currently growing. This makes teacher's self-development and professional self-realization the key problem in improving his professional culture level (Nemov, 2004).

Thus, pedagogic activity success of prospective teacher depends on the level of development of his personality and pedagogic self-regulation, which is the teacher's regulation of his own opportunities in accordance with the professional activity requirements (Baranova, 2008).

\subsection{Moral self-regulation}

Personality self-regulation is the adjustment of one's behavior in accordance with social and professional moral regulations. The most efficient personality phenomenon of behavior self-regulation is moral categories. Moral selfregulation is a process, which defines personality's ability to adjust its behavior to conventional moral regulations and professional requirements. This implies that the person actively sorts the influences of the social environment and determines his own attitude towards them. Self-regulation is not limited to the choice of single actions, it also consists of personality self-settlement. In order to provide this, personality has a multi-level system of internal mechanisms or processes, which happen in its moral conscience and provide a robust link between external requirements, presented as social and professional moral regulations, and the behavior. The person regulates his activity and behavior through reflection and experiencing of these regulations.

Considering the above-stated, we also highlight the significance of internal factors stimulation for the development of moral self-regulation abilities and of the internal processes, necessary for teacher's personality self-regulation. These factors include empathy, decision-making, freedom of choice in behavior, actions, reflection, self-analysis and selfesteem, mental correction of one's own states and behavior.

Teacher's moral self-regulation consists of voluntary drive to compare his actions, intentions and interests with the interests, actions and intentions of his students and to encourage himself to act upon their interests. During his mentoring 
activity the teacher has to resolve occurring situations, which are impossible to predict and, consequently, it is impossible to model all ways to resolve them. Due to this fact, it is highly significant for the teacher to develop the ability to creatively imply the basic moral regulations in various conflict-solving situations and to adjust those regulations to the changing life conditions and growing social requirements towards teacher's moral image and behavior.

\subsection{The main components of self-regulation}

In order to master the abilities of conscious self-regulation, it is important for the students to learn not only about the phenomenon of self-regulation but also about the functioning of self-regulation mechanism, the structure of which includes several components. These components are: the moral component - moral knowledge and concepts, professional requirements towards teacher's personality and activity; evaluation component - evaluation and selfevaluation, conscious criteria of the evaluation of teacher's personality, activity and communication; regulation component - feelings, attitudes, beliefs, which regulate teacher's behavior, activity and communication; behavioral component voluntary processes, self-control, self-correction of the behavior, personality and activity (Andreev, 2008).

The integral analysis of teacher's self-regulation should be conducted with simultaneous regard to conceptual, dynamic and resultative characteristics. Conceptual characteristics of self-regulation include: 1) goal-setting in the fulfilment of teacher's personality needs, motives, interests, affirmations and relations; 2) beliefs, values, ideals; 3) level of aspiration, self-esteem, system of social beliefs (Osnitskiy, 2009).

Dynamic personality characteristics of self-regulation include the analysis of the behavior: power, intensity, velocity, plasticity and robustness of actions. Resultative characteristics of self-regulation include the analysis of the effectiveness of completed actions in common situations, as well as in extremal conditions.

It has been shown that teachers, who have the skills of conscious self-regulation, have the following advantages:

1. They are less aggressive, they live in harmony with themselves and with the surrounding world.

2. They have better abilities to adapt socially and psychologically to constantly changing environment.

3. They are highly productive and successful in professional activity.

4. Their professional and personal self-actualization is highly possible.

Therefore, teacher's self-development of conscious self-regulation skills has practical value, because it allows the teacher to prevent personal and professional deformations and to reach the harmony with himself and with the world.

The success of self-regulation abilities development in pedagogic activity depends on several conditions. The main of them include:

1. Well-developed system of long-term, robust and positive motivational states: interest, dedication to the pedagogic work, responsibility, positive affirmations towards pedagogic activity, professional values, all of which create the basic level of teacher's self-regulation. Moreover, during teaching and mentoring process it is useful to plan the self-regulation as an ability to produce and use the states, which stimulate cognitive activity of the students through their own involvement, peak of creativity, optimal working state.

2. Well-developed mechanism of self-regulation, which is a secluded loop, includes four main blocks:

- goal and self-programming of pedagogic activity;

- functional block of programming, which includes subjective model of significant activity conditions and the program of executive actions itself;

- evaluation block for the results of self-regulation system, which includes the creation of results success criteria and results evaluation itself, according to the chosen criteria;

- correction block for the pedagogic activity, which implies the correction of activity goal, of significant conditions model and of executive actions program.

The conditions, necessary for the teacher to develop conscious self-regulation abilities, are the presence of internal motivation, the ability to use self-regulation mechanism, well-developed basic, current and operative levels of selfregulation.

\subsection{Methods of mental states optimization}

In order to optimize a mental state, self-regulation uses various methods - autogenic training, meditation, physical exercise, self-massage, neuromuscular relaxation, visualization, breathing techniques, aromatherapy, neuro-linguistic programming, art therapy, color therapy, etc. (Nemov, 2004).

Autogenic training is useful in the types of activity that cause exceeding emotional stress, which includes teaching jobs, because often, during the communication between the teacher, the children and their parents, difficult situations 
occur and require emotional and voluntary self-regulation. Using autogenic training techniques allows a person to willfully change his mood and emotional state, which has a positive effect on his health. Autogenic training increases working capacity, thus increasing pedagogic feedback as well (Aleksandrov, 2007).

Neuromuscular relaxation is a system of special exercises for relaxing different muscle groups. The aim of such training is o relieve muscle tension, which is directly related with various types of negative emotional arousal - fear, anxiety, embarrassment. By decreasing or preventing muscle tension it is possible to relieve stress states, insomnia, migraines, as well as to normalize emotional background (Baranova, 2008).

Visualization has always been one of the methods, commonly used by many philosophers to reach tranquility. Ability to visualize makes enrich a person's inner world, increase his creativity and empathy and sharpen the intuition. Vivid imagination of the desired outcome leads to positive thinking (Irzhanova, 2005).

Meditation is a classic way of concentrating, relieving psychological and emotional stress, mental and physical fatigue. Meditation decreases stress level and brings inner tranquility and satisfaction with life. Meditation exercises lower the need in external medical assistance. In the field of personality development meditation helps strengthening inner psychological structure, thus increasing person's self-esteem and independence from other people's opinions and creating confident, calm and optimistic point of view and perception of life. In the field of education and teaching meditation is successfully used to develop psychological cognitive processes, such as perception, attention, memory, thinking, imagination, which, in turn, improves understanding of learning subject; meditation also increases creativity potential and working capacity of the professional activity (Prokofjev, 2003).

An important source of stabilizing emotional state of any person is breathing. By learning to breathe correctly and to use breathing in different life circumstances, the teacher will get one more method of emotional self-regulation. Breathing can be consciously controlled, and we can manage our breathing to a certain extent, thus affecting internal organs activity (Bakh, 2008).

Aromatherapy is a science and an art of scents influence on a person's mental and physical state. It is used as a way of preventing overload, irritation and depression. There are certain recommendations about the use of various scents depending on a person's temper, gender, time of day or period of year. It is known that in the morning citrus scent can increase working capacity. Jasmine, eucalyptus and lemon lower stress levels. Lavender and anise oils positively influence interpersonal contacts. Rosemary and jasmine scents increase memory and attention (Bildanova \& Shagivaleeva, 2009).

During practical lessons students also learn the basics of self-massage. There are special points in the mouth, on the ears, palms and soles of the feet. By massaging these points it is possible to regulate the functions of all internal organs. As it has been revealed in Eastern medicine, massaging the thumbs increases working capacity of the brain (IShen, 2007). Regular self-massage allows to strengthen the body, increase its resistance to tonsillitis, bronchitis and sinusitis, which are known to be teachers' professional diseases.

Neuro-linguistic programming is currently used as a method of mental states self-regulation. It includes a set of exercises, which help to recover personality resources (Sandomirskiy, 2009). By knowing himself, his needs and ways of their satisfaction, a person can distribute his energy more rationally and efficiently throughout each day or the whole school year.

Positive thinking is determined by a person's belief in his own potential, high self-esteem and optimistic point of view, which develops during the education and, more importantly, during self-education. Positive thinking implies unconditional self-love and self-acceptance. The teacher knows that patience, tranquility and self-confidence are important conditions for effective pedagogical activity. By exercising voluntary patience and deliberation the teacher may develop a more moderate speed of actions, higher restraint in previously unsettling situations.

\section{6 "Bibliotherapy" method}

During the practical lessons students also become familiar with the "bibliotherapy" method. T.Yu. Koloshina \& A.A. Trus, who studied the ways of using art-therapy in business-trainings, define bibliotherapy as "a field of art-therapy, which is based on the healing influence of the word, i.e. on the self-expression through creative writing" (Koloshina \& Trus, 2010). They point out that bibliotherapy is difficult for the training coach but has a therapeutic potential, based on "Hennequin's law, according to which the main character of the story is always the author. By changing the language of expression we change the state, by changing the metaphor we change the life perspective" (Koloshina \& Trus, 2010).

Bibliotherapy potential of psychological correction includes psychological mechanisms: catharsis, dissociation, revelation and study of the emotional state, clearance and understanding of author's deep values and resources. Writing fiction gives the author an opportunity to make an indirect confession (Ljubimova, 2006). 
While learning this method, students are suggested to write "experimental poetry". They used the following poetry forms: hokku, free verse, rhopalique, limerick, approximate rhyme, calligram, heterogram, veiled poem, letterist poem, cento, one-line verse, minimalistic poem, ghazal.

Learning the algorithms of experimental poetry forms was carried out during interactive lessons and was organized the following way: each student, as a literature expert, made a presentation of "their" poetry form; after the presentation students had 15 minutes to write a poem according to the algorithm. Such sequence of actions allowed to pass the barrier of "I am not a poet" and to compose a "poetry toy". Interactive lesson provided every student with the support and with the teacher's comments. During the task the teacher observes, how the idea of creative writing itself is being accepted (notes, whether it has external resistance, reads the poems, gives recommendations for improving the form, rhythmic structure, expressive means and assesses the aesthetic quality of the poems.

During the final lesson each student chose three best of his poems, presented them on A3-formatted sheets (to ensure compositional unity), which then participated in the exhibition of the creations.

Public presentation is very significant for the organization of the final part of creative process (Sandomirskiy, 2009). This action allows solving the following tasks: a) helping the students to see themselves as the "authors" of a fictional work; b) feeling the moment of separating the creation from the creator; c) experiencing oneself as a public author, who receives reviews of his work; d) feeling the emotions of co-authorship; e) experiencing oneself as the recipient of the art, who knows the technology of creating those pieces of art.

The experience in leading interactive bibliotherapy lessons and the analysis of reflexive reports allowed to make the following conclusions: bibliotherapy lessons of writing poetry have a high effect on mental state optimization; students gain positive experience of being poetry authors, create their own texts without stress and inner resistance, reach the highest aesthetic level of art perception, learn art-therapy methods with the opportunity to relieve psychological and emotional stress and receive a more positive life perspective. In order to reach the highest effect it is necessary to follow these rules: a) high quality of bibliotherapy technology; b) group participation in the interactive lessons for the presentation of multiple poetry forms; c) leading teacher's professional integrity; d) high-quality feedback throughout every step of creative process (Oganesyan, 2007).

Thus, during the professional activity and self-education, every teacher finds and uses various methods and means of self-regulation, which helps to influence his emotional state, to control and to regulate external psychological expressions. The protection of one's physical and mental health depends on the person himself, on his ability and desire to use certain methods and techniques of psychological self-regulation.

\section{Methods}

Participants in the study were students in the age of 17 to 22 years old. In order to assess stress levels and stress resistance we used "Test of stress resistance" (Scherbatykh, 2006). This test includes six scales, each of which has five questions. Each event (question) can be evaluated with 10-points system by assigning any number from 1 ("does not concern completely") to 10 ("severely disturbs and stresses out").

First group of questions assesses the reaction to the circumstances, which we are not able to influence. Such circumstances include high prices, unexpectedly bad weather, and strict teacher. Maximum possible score is 50 points, minimal score - 5 points. Mean scores range from 15 to 30 points. Higher score means subject's stronger reaction to the circumstances, which affects stress sensitivity and stress resistance levels.

Second scale reveals the tendency to overcomplicate everything, which can lead to increased stresses. This group includes questions about shyness, embarrassment, fears of failures, thoughts about possible troubles and problems, pessimism, tendency to notice mostly negative things in life. Mean scores range from 14 to 25 points.

Third scale assesses the predisposition towards psychosomatic diseases. The questions address stress influence on the health, which has to be evaluated with 10-point system as well. Such factors include heartaches, trouble with breathing and digestive system, muscle tension, headaches, high fatiguability. Mean scores range from 12 to 28 points.

Fourth scale evaluates the destructive ways of coping with stress. The examples of such coping mechanisms include smoking, watching television, aggression. Mean scores are 10 to 22 points.

Fifth score evaluates constructive coping strategies. Such ways to relieve stress, as sleep, rest, activity change, communication with friends, physical activity, analysis of one's own actions, search for other solutions, change of one's behavior in the current situation, have to be evaluated with 10-point system. Mean scores are 23 to 35 points.

Sixth scale evaluates, how stress level has changed during the last three years (whether it has significantly declined, has insignificantly declined, has not changed, has insignificantly increased or significantly increased).

While working with the test, the participants can analyze their own results and discuss them with the teacher. 
The test evaluates stress sensitivity level, which is a characteristic, opposed to stress resistance. Scores ranging from 70 to 100 points are considered satisfactory.

Dynamic stress sensitivity level represents the ability to resist stress with appropriate behavior. Scores from 35 to 86 points are considered normal for this characteristic.

\section{Results}

As a result of the study, the following data were obtained: $82 \%$ of the students have medium scores for the reaction to the circumstances, which cannot be influenced, $9 \%$ have increased reaction to these circumstances, which affects the level of stress sensitivity and stress resistance, $9 \%$ have adequate reactions towards the surrounding circumstances.

$30 \%$ of the students have the tendency to overcomplicate everything, which may lead to stress, $70 \%$ of the students have an adequate attitude towards their learning, they have no pessimism, no fear of the future and no shyness.

$25 \%$ of the students have a predisposition to psychosomatic diseases and the most frequent of their symptoms are headaches and increased fatiguability, while the least frequent are heartaches and trouble breathing. $75 \%$ of the students have medium scores (within the normal range) of predisposition to psychosomatic diseases.

As a destructive coping mechanism, students choose watching television. The least frequent choice was aggression (taking the rage out on another person).

$90 \%$ of the participants choose constructive strategies of coping with stress. The most frequent mechanisms were sleep, rest, change of the activity, communication with friends. $55 \%$ of the students use physical ways of stress relief. 10 $15 \%$ choose such methods, as the analysis of their actions and search for another solutions, $5 \%$ change their activity in the current situation. $10 \%$ do not use constructive mechanisms of stress relief enough.

Participants in the study were first-year and fifth-year students. $60 \%$ of first-year and $75 \%$ of fifth-year students have normal stress resistance level.

Overall results show that $40 \%$ of the students have high stress resistance level - high ability to cope with stress by using adequate behavior. $40 \%$ of students have normal stress resistance level, $20 \%$ of students have elevated stress sensitivity, i.e. decreased stress resistance.

\section{Discussion}

Most of the students, who participated in the study, indicated communication with friends and loved ones as the main way to overcome stress; more than a half of the subjects look for the support from their relatives and significant others. Approximately half of the respondents (58\%) relieve the stress by physical activity. We also revealed that $40 \%$ of 5 -year students have high stress resistance levels. Such students tend to present minimal levels of stress load. Any person's activity of any type has higher efficiency when stress resistance level is also high. This allows analyzing management activity as the one that has a high level of stress load. Such students do not waste their energy and resources on fighting negative mental states, which occur during the stress. Therefore, their activity becomes more efficient, regardless of the area and type of the activity. $40 \%$ of the students have liminal (medium) level of stress resistance. Their stress resistance declines with the increase of stressful life situations amount. This leads to the fact that the person has to spend a significant amount of energy and resources on coping with negative mental states caused by stress. $20 \%$ of the students have low stress resistance level. Such students present high levels of stress load, they demonstrate low stress resistance (vulnerability). This causes the person to spend most of the energy and resources on coping with negative mental states in stressful situations.

\section{Conclusion}

A prospective teacher needs to master all fields of professional activity: teaching, mentoring, pedagogic communication, using means of personality self-actualization, reaching high results in students' education and manners, all of which demands high emotional commitment. A teacher, who has worked for a long time, develops an individual style of activity, gains experience, but also accumulates "mental fatigue". Teacher's job is accompanied by high amounts of internal work and high complexity, which leads to fatigue and sometimes to exhaustion. Learning to be a teacher implies not only the development of teacher's personality, skills and knowledge, but also the occurrence of such negative consequences, as decreasing health, fatigue, aggression, which affects the communication with children and colleagues. Due to these facts, one of the significant aspects of teacher's professional activity is the self-regulation of mental and emotional state.

Protection of one's own physical and mental health depends on the person himself, his desire and ability to use 
various means of psychological self-regulation. The particular choice of self-regulation methods and means depends on the person's individual psychological characteristics. Therefore, specialist's successful professional activity is mediated by individual differences in mental states self-regulation. This leads to the following tasks in our future research:

1. Studying the relation between personality individual differences and mental states self-regulation.

2. Revealing the potential of art therapy methods in providing techniques for mental state self-regulation.

Thus, educating prospective teachers about self-regulation, motivational basis of this process and mechanisms of its realization on the levels of personality, behavior and activity has not only theoretical, but practical value as well. It allows preventing personal and professional deformations during specialists' personal and professional development.

\section{References}

Aleksandrov, A.A. (2007). Autotrening: Spravochnik. SPb.: Piter, p. 272.

Andreev, V.I. (2008). Pedagogika vysshey shkoly. Innovatsionno-prognosticheskiy kurs. Kazan: Tsentr innovatsionnyh tehnologiy, p. 500.

Bakh, B. (2008). Lechebnye gimnastiki. M.: AST; Kiev: NKP, p. 188.

Baranova, S.V. (2008). Nauchis otdyhat!: Tehniki relaksatsii. Rostov-na-Donu: Feniks, p. 156.

Bildanova, V.R., Shagivaleeva, G.R. (2009). Osnovy psihicheskoy samoreguliatsii: uchebnoe posobie dlia studentov vysshih uchebnyh zavedeniy. Elabuga: Izd-vo EGPU, p. 116.

Dyshkov, B.A., Korolev, A.V., Smirnov, B.A. (2005). Entsiklopedicheskiy slovar: Psihologiya truda, upravleniya, inzhenernaya psihologiya i ergonomika, p. 350.

Irzhanova, L.S. (2005). Pobedi stress!: treningi na pozitivnoe myshlenie. Rostov-na-Donu: Feniks, p. 249.

I-Shen (2007). Vostochnye priemy ozdorovleniya. SPb.: Nevskiy prospekt: Vektor, p. 236.

Koloshina, T.Yu., Trus, A.A. (2010). Art-terapevticheskie tehniki v treninge: harakteristiki i ispolzovanie. Prakticheskoe posobi dlia trenera. SPb.: Rech, p. 189.

Lomov, B.F. (1984). Metodicheskie i teoreticheskie problemy psihologii. M.: Nauka, p. 444.

Lyubimova, N.V. (2006). Samoistselenie tvorchestvom i adaptatsiey k zhizni. Metody psihologicheskoy samopomoschi (Psihologicheskiy praktikum). Rostov-na-Donu: Feniks, p. 64.

Mensh, E.A. (2012). Faktory, vliyajuschie na formirovanie tsennostnogo otnosheniya studentov k zdorovyu. Aktualnye voprosy sovremennoy pedagogiki: materialy II mezhdunarodnoy nauchnoy konferentsii, Ufa, iyul 2012, p. 180.

Nemov, R.S. (2004). Psihologiya. Kn. 1. M.: Prosveschenie: Vlados, p. 576.

Oganesyan, N.T. (2007). Praktikum po psihologii tvorchestva. M.: Flinta, Moskovskiy psihologo-socialnyi institut, p. 344.

Osnitskiy, A.K. (2009). Struktura i funktsii regulyatornogo opyta v razvitii subjektnosti cheloveka. Subjekt i lichnost v psihologii samoreguliatsii: Sbornik nauchnyh trudov, ed. Morosanova, V.I., M.: Stavropol: Izd-vo PI RAO, SevKavGTU, p. 350.

Prokofyev, L.E. (2003). Osnovy psihicheskoy samoreguliatsii. SPb.: Izd-vo Lan, p. 67.

Sandomirskiy, M.E. (2009). Zaschita ot stressa. Rabota s podsoznaniem. SPb.: Piter, p. 304.

Scherbatykh, Yu.V. (2006). Psihologiya stressa i metody korrektsii. SPb.: Piter, p. 256.

Tkacheva, E.G. (2010). Formirovanie opyta professionalno-lichnostnoy samoregulyatsii buduschego pedagoga v processe fizkulturnoy deyatelnosti: dissertatsiya ... kandidata pedagogicheskih nauk. Volgograd, p. 196.

Zanina, L.V. (1994). Stanovlenie gumannoy pedagogicheskoy pozitsii buduschego uchitelya $v$ usloviyah mnogourovnevoy sistemy vysshego pedagogicheskogo obrazovaniya: dis. ... kand. ped. nauk. Rostov-na-Donu, p. 199. 